Yurij Stetsyshyn, Volodymyr Donchak, Khrystyna Harhay and Stanislav Voronov

\title{
MAIN REGULARITIES OF POLYETHYLENETEREPHTALATE SURFACE MODIFICATION BY OLIGOPEROXIDES
}

\author{
Lviv Polytechnic National University, \\ 12 Bandera str., 79013 Lviv, Ukraine \\ yrstecushun@ukr.net
}

Received: May 12, 2008

\begin{abstract}
The polyethyleneterephtalate surface has been modified with new oligoperoxides, synthesized on the base of pyromellitic acid chloroanhydride, polyethylene glycol-9 and tert-butylperoxymethanole. The developed method allows to achieve the degree of surface modification up to $64 \%$. Ability of dextrane macromolecules attaching onto peroxidized surface has been shown. The correlation between the degree of surface modification and oligoperoxide concentration in solution, temperature and time of the modification process has been established.
\end{abstract}

Keywords: peroxidation, modification, polymer surface, oligoperoxide, polyethyleneterephtalate.

\section{Introduction}

One of the general tendencies of polymeric chemistry development is modification of polymer surface so that the material could acquire specific surface properties and simultaneously could keep physical, mechanical and other three-dimensional ones. The chemical modification of polymeric materials surface as a rule demands its previous activation, which can be carried out by plasma treatment, UV- or $\gamma$-irradiation, by chemical methods - oxidation, ozonation or treatment with organic peroxides or by formation of specific functional groups on the surface. Today the peroxidation of the surface is considered to be one of the most promising methods for its activation $[1,2]$ and a series of articles, reviews and patents is devoted to solution of this problem $[3,4]$. Effective modifiers of polymer surface use to be polymer and oligomer peroxides $[5,6]$.

The characteristics of peroxidated surface depend on the nature of substrate and polyperoxide, the thickness and character of attaching polyperoxide nanolayer to a substrate surface, the amount of peroxide groups in polyperoxide etc. [7]. So, peroxidized polymer surface with the uniform distribution of peroxide groups is being formed as well.

Formation of covalent-attached polyperoxide nanolayer with uniform distribution of active peroxide groups opens the way to grafting a layer of some hydrophilic polymer or natural polysaccharide for forming the materials with specific surface properties. Therefore, investigation of peroxidation regularities of polymer substrate surfaces by oligoperoxides with the further formation of attached polymer layers is an up-date task.

\section{Experimental}

\subsection{Materials}

Pyromellitic dianhydride (PMDA) of $98.5 \%$ purity was sublimated under the pressure of $270 \mathrm{~Pa}$. The melting temperature determined by calorimetric analysis is $560 \mathrm{~K}$ and it is in good agreement with literature data [8]. Acid number (A.N.) is $1031 \mathrm{mg} \mathrm{KOH} / \mathrm{g}$; calculated value is $1029 \mathrm{mg} \mathrm{KOH} / \mathrm{g}$.

Pyridine and organic solvents were previously purified in accordance with classical techniques described by Weissberger [9]. Their characteristics were the same as reported in literature. Polyethylene glycols PEG-9 was from Merck Chem. Co.

Tert-butylhydroperoxide (TBHP) was obtained according to a classical procedure [10] and purified by vacuum rectification. The fraction boiling in the range of $318-320 \mathrm{~K}$ under the pressure of $1.6 \cdot 10^{3} \mathrm{~Pa}$ was withdrawn. The refractive index $\mathrm{n}_{\mathrm{d}}{ }^{20}=1.4008$ and the density $\mathrm{d}_{4}{ }^{20}=0.8957$, which were in good agreement with literature values [11]. Content of active oxygen was $17.6 \%$ (calc. $17.7 \%$ ).

Tert-butylperoxymethanol (TBPM) was synthesized using the method developed by Dickey [12]. After vacuum distillation $\left(322-323 \mathrm{~K}\right.$ at $0.5 \mathrm{M} 10^{3} \mathrm{~Pa}$ ) its $\mathrm{n}_{\mathrm{d}}{ }^{20}=1.4127$ (lit. $\left.\mathrm{n}_{\mathrm{d}}^{20}=1.4128[12]\right)$ and the content of active oxygen was $13.30 \%$ (calc. $13.33 \%$ ).

Tetrachloroanhydride of pyromellitic acid. In a $500 \mathrm{ml}$ round bottomed flask equipped with a thermometer and a reflux condenser, connected with water scrubber, $43.6 \mathrm{~g}(0.2 \mathrm{~mol})$ PMDA and $91.6 \mathrm{~g}(0.44 \mathrm{~mol}) \mathrm{PCl}_{5}$ were mixed and boiled on the oil bath until the reaction mixture became homogeneous with the additional 15-16 h. The temperature of reaction mass was $405-408 \mathrm{~K}$. The reflux condenser was then replaced by a Liebig condenser and 
approximately $60-63 \mathrm{~g}$ of $\mathrm{POCl}_{3}$ was distilled off during $8 \mathrm{~h}$. At the end of the process the mixture was heated up to $455-458 \mathrm{~K}$. The crude product was then recrystallized from the gasoline yielding $51.2 \mathrm{~g}(78.1 \%)$ of a colorless crystalline product with m.p. $=337 \mathrm{~K}$ (lit. m.p. $337 \mathrm{~K}$ [13]), A.N. = 1373 (calc.1368).

Formula of oligoperoxide with primary-tertiary dialkyl peroxy groups (PMP) is represented in Fig.1a.

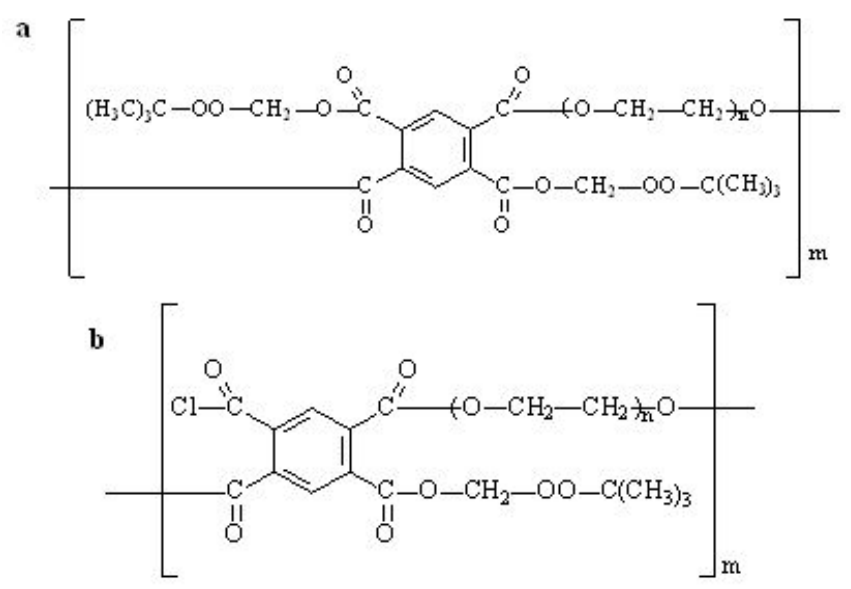

Fig. 1. Oligoperoxide on the basis of tetrachloroanhydride of pyromellitic acid, PEG-9 and TBPM, n=9, m=3-5 (PMP) (a) and oligoperoxide on the basis of tetrachloroanhydride of pyromellitic acid, PEG-9 and TBPM containing residual chloroanhydride groups, $n=9, m=3-5$ (PMCP) (b).

In a three-necked reactor, equipped with a stirrer, a thermometer and a funnel droplet, $4.0 \mathrm{~g}(0,0122 \mathrm{~mol})$ of tetrachloroanhydride of pyromellitic acid were dissolved in $20 \mathrm{ml}$ of arid dichloroethane and $2.9 \mathrm{~g}(0.0244 \mathrm{~mol})$ of TBPM were added. The reactive mixture was cooled down to $273 \mathrm{~K}$ on the ice bath and $1.93 \mathrm{~g}(0.0244 \mathrm{~mol})$ of pyridine, dissolved in $10 \mathrm{ml}$ of arid dichloroethane, were added dropwise, in such a manner, that the temperature does not rise higher than $278 \mathrm{~K}$. The mixture was stirred for $1 \mathrm{~h}$. Then $5 \mathrm{~g}(0.0122 \mathrm{~mol})$ of polyethylene glycole (PEG-9) were added and at 273-278 K - solution of $1.93 \mathrm{~g}(0.0244 \mathrm{~mol})$ pyridine was added in $10 \mathrm{ml}$ of arid dichloroethane dropwise. The mixture was stirred the next $3 \mathrm{~h}$, gradually raising the temperature up to $288-293 \mathrm{~K}$. The precipitate of pyridinium chloride was filtered out. The filtrate obtained was washed by $2 \%$ solution of HCL, and then by water until $\mathrm{pH} 4-5$ was obtained. The oligomer was precipitated by hexane and dried in vacuum $(0.1 \mathrm{~Pa})$ at $313 \mathrm{~K}$ for $3 \mathrm{~h} .8 .4 \mathrm{~g}$ (yield $=81 \%$ ) of PMP were obtained. It looks like a slightly yellow resin with active oxygen content of $3.64 \%$ (calc. $3.7 \%$ ), residual acid number $7 \mathrm{mg} \mathrm{KOH} / \mathrm{g}$ and the determined molecular mass (cryoscopy in dioxane) about 2400.

Oligoperoxide with residual chloroanhydride groups (PMCP). Its formula is represented in Fig. $1 b$.
$4.0 \mathrm{~g}(0.0122 \mathrm{~mol})$ of tetrachloroanhydride of pyromellitic acid were dissolved in $20 \mathrm{ml}$ of arid dichlorethan, placed in a three-necked flask, equipped with a stirrer, and then $1.46 \mathrm{~g}(0.0122 \mathrm{~mol})$ of TBPM were added. The reaction mixture was cooled down to $273 \mathrm{~K}$ and then $0.96 \mathrm{~g}(0.0122 \mathrm{~mol})$ of pyridine, dissolved in 10 $\mathrm{ml}$ of arid dichlorethane were added dropwise, making sure the temperature does not rise higher than $278 \mathrm{~K}$. Mixing continued at the temperature of 273-278 K for $1 \mathrm{~h}$. Then $5 \mathrm{~g}$ (0.0122 mol) PEG-9 was added and again the solution $1.93 \mathrm{~g}$ of pyridine in $10 \mathrm{ml}$ of arid dichlorethane was added dropwise. Then the mixture was stirred during next $3 \mathrm{~h}$, with gradual rising of the temperature up to $288-293 \mathrm{~K}$. The precipitate of pyridinium chloride was filtered out. The solvent was distilled out and the residue was dried in vacuum $(0.1 \mathrm{~Pa})$ at $313 \mathrm{~K}$ for $3 \mathrm{~h}$. The yield of oligoperoxide was $9.2 \mathrm{~g}(98 \%)$. It looked like slightly yellow resin. Its characteristics were the following: active oxygen content was $1.8 \%$ (calc. $2.2 \%$ ), content of active chlorine was $3.8 \%$ (calc. $4.7 \%$ ).

\subsection{Modification of the polyethyleneterephtalate (PET) surface}

Modification of PET surface and examination of the main regularities of this process were held by using synthesized oligoperoxides - PMP and $P M C P$, Figs. 1a and $b$. The covering of oligoperoxide solution on PET surface was accomplished by using a "spin-coating" method [14]. After the uniform distribution of the solution on the surface of the plate the sample was heated for definite time (see Fig. 3). After the thermal treatment the unattached modifier has been extracted by acetonitryle, then by water and dried at room temperature.

For installing of the dextrane layer the PET plate was immersed into $1 \%$ water solution of dextrane and heated in solution at $353 \mathrm{~K}$ during definite time, mentioned in Table 2. After the extraction from the solution the plates were washed by water and dried at room temperature.

\subsection{Determination the free surface energy of polymer materials}

Modification of the surface by olygoperoxides was controlled by changing the wetting angles of two liquids of modified and original surfaces of PET [15]. It is important that determination of wetting angles allows to evaluate the free surface energy, its hydrogen and dispersion constituents, as well as the degree of surface modification, and also the change of free surface energy when modifying the surface.

Wetting angles of two liquids - water and methylene iodide were measured. 4-5 drops of the correspondent liquid were placed, using micro syringe, on the surface of the PET plate with the size of 
$0.01 \times 0.0005 \mathrm{~m}^{2}$. The container with plates was thermostated at $293 \mathrm{~K}$ for $15 \mathrm{~min}$, in order to achieve the balance. Then values of wetting angles for the drops were measured. The amount of parallel measurements per one kind of plates was 12 .

The evaluation of surface energy constituents was made by using the method of two liquids, according to the following equation:

$$
1+\cos \theta=2\left[\frac{\left(\lambda_{s}^{d}\right)^{1 / 2}\left(\lambda_{l}^{d}\right)^{1 / 2}}{\lambda_{l}}+\frac{\left(\lambda_{s}^{h}\right)^{1 / 2}\left(\lambda_{l}^{h}\right)^{1 / 2}}{\lambda_{l}}\right]
$$

where $\lambda$ - surface tension, $\mathrm{mN} / \mathrm{m}$; lower indexes $s, l$ belong to the surface tension of the solid material (plate) and liquid, respectively; upper indexes $d, h$ indicate the contributions of dispersion and hydrogen bonding, respectively; $\theta-$ contact wetting angle.

The solution of the system of the two abovementioned equations for two different liquids and the substitution of corresponding data allow to determine the surface tension constituents.

\subsection{Determination of the modification degree of the polymer surface}

The modification degree was calculated as a part of the surface, occupied by oligoperoxide or other modifier. For the surface, which includes parts with different values of wetting, the Kassie equation was used [16]:

$$
\cos \theta=x \cos \theta_{1}+(1-x) \cos \theta_{2}
$$

where $x$ - part of the surface, occupied by the sections 1 ; (1-x) - part of the surface, occupied by the parts of the $2^{\text {nd }}$ type; $\theta_{1}-$ contact angles of the liquid on the homogeneous surface of the $1^{\text {st }}$ type; $\theta_{2}$ - contact angles of the liquid on the homogeneous surface of the $2^{\text {nd }}$ type; $\theta-$ contact angle of the investigated surface.

Cosine of the contact angle of the surfaces under investigation - is an average cosine of different contact angles of the heterogeneous surfaces. Knowing the values of cosines of the contact wetting angles on the homogeneous surfaces of the $1^{\text {st }}$ and $2^{\text {nd }}$ types, it is possible to define the level of chemical heterogeneity of the modified surface as well as the part of the modified surface.

\section{Results and Discussion}

Acetonitryle was used as a solvent for oligomers. It is important to mention, that molecules of acetonitryle are thermodynamically alike with macromolecules of PET (the PET solubility parameter is $(19.8-21.8) \cdot 10^{3} \mathrm{~J}^{1 / 2} / \mathrm{m}^{3 / 2}$, while the acetonitryle parameter is $23.9 \cdot 10^{3} \mathrm{~J}^{1 / 2} / \mathrm{m}^{3 / 2}$ ) [17]. Therefore molecules of acytonitryle diffuse onto the surface (upper) layer of PET and cause its swelling, which assists in further attaching of oligoperoxide to the surface.

The values of the contact wetting angles of unmodified and modified surfaces by water and methylen iodide, as well as correspondently estimated values of free surface energy and its constituents are shown in Table 1. It also presents the value of the contact wetting angle by water and methylene iodide of the oligoperoxide surface. It should be noted, that in this very case the tests were held using the layer of the oligoperoxide applied over PET surface, and then heated. It can be seen from Table 1, that modification of the PET surface significantly changes the value of free surface energy and, results in significant increasing of its hydrogen component and minor decreasing of the dispersion one.

The literature source [18] states that the degree of surface modification with polyperoxides depends on the thickness of polyperoxide layer applied, and consequently on initial concentration of polyperoxide in a solution. In order to understand the process of modification, it would be helpful to investigate the dependence of the modification degree of PET surface on the concentration of a modifier in the solution. These dependences for our oligoperoxides are presented in Fig. 2. The obtained values allow us to make the following conclusion: the maximum possible modification of the surface can be reached when the concentration of oligoperoxide in the acetonitryle solution is not less than 4 mass $\%$.

We can see from Fig. 2 that PMCP is a more effective surface modifier, compared with PMP. This fact can be explained by the ionic interaction of chloroanhydride groups of oligoperoxide with some polar fragments of PET, which eases fixing of the first modifying layer.

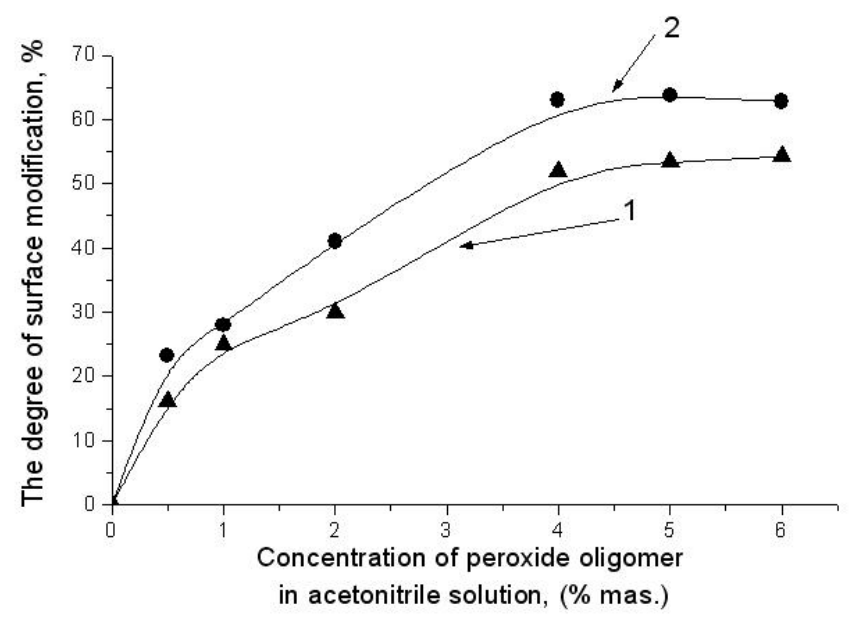

Fig. 2. Dependence of the modification degree for PMP (curve 1) and PMCP (curve 2) on the concentration of the oligoperoxide in the acetonitryle solution 
The characteristics of different chemical nature surfaces

\begin{tabular}{|c|c|c|c|c|c|c|c|}
\hline \multirow[t]{2}{*}{ Sample № } & \multirow{2}{*}{ Investigated surface } & \multirow{2}{*}{$\varphi \mathrm{H}_{2} \mathrm{O},{ }^{o}$} & \multirow{2}{*}{$\varphi \mathrm{CH}_{2} \mathrm{I}_{2},{ }^{o}$} & \multicolumn{3}{|c|}{$\begin{array}{l}\text { Components and total } \\
\text { surface energy, } \mathrm{MN} / \mathrm{M}\end{array}$} & \multirow{2}{*}{$\begin{array}{c}\text { The } \\
\text { modification } \\
\text { degree of the } \\
\text { surface, } \%\end{array}$} \\
\hline & & & & $\lambda_{S}^{d}$ & $\lambda_{S}{ }^{h}$ & $\lambda_{S}$ & \\
\hline 1 & PET & $80 \pm 3$ & $25 \pm 1.5$ & 47.5 & 2.2 & 49.7 & - \\
\hline 2 & Layer of PMP & $24.5 \pm 3$ & $12 \pm 1.5$ & 35.2 & 34.2 & 69.5 & - \\
\hline 3 & Layer of PMCP & $26.5 \pm 2.3$ & $12 \pm 1.9$ & 35.5 & 33.2 & 68.7 & \\
\hline 4 & PET—PMP & $55 \pm 1.8$ & $18 \pm 1.6$ & 39.2 & 15.4 & 54.6 & 54 \\
\hline 5 & PET—PMCP & $50 \pm 1.8$ & $16 \pm 1.6$ & 38.6 & 18.2 & 57.8 & 64 \\
\hline
\end{tabular}

Note: PET + PMP or PMCP - the surfaces, obtained by coating of PET surface with $5 \%$ solution of PMP or PMCP, respectively, using a spin coating method and further heating at $353 \mathrm{~K}$ during $4 \mathrm{~h}$.

The characteristics of the PET surfaces modified with peroxy oligomers and dextrane

\begin{tabular}{|c|c|c|c|c|c|c|c|}
\hline \multirow{2}{*}{$\begin{array}{l}\text { Sample } \\
\text { № }\end{array}$} & \multirow[t]{2}{*}{ Investigated surface } & \multirow[t]{2}{*}{$\varphi \mathrm{H}_{2} \mathrm{O},{ }^{o}$} & \multirow[t]{2}{*}{$\varphi \mathrm{CH}_{2} \mathrm{I}_{2}}$, & \multicolumn{3}{|c|}{$\begin{array}{c}\text { Components and total surface } \\
\text { energy, } \mathrm{MN} / \mathrm{M}\end{array}$} & \multirow[t]{2}{*}{$\begin{array}{c}\text { The modification } \\
\text { degree of the } \\
\text { surface, } \%\end{array}$} \\
\hline & & & & $\lambda_{S}{ }^{d}$ & $\lambda_{S}^{h}$ & $\lambda_{S}$ & \\
\hline 1 & PET-PMP & $62 \pm 1.8$ & $20 \pm 1.6$ & 40.3 & 11.1 & 51.4 & 40 \\
\hline 2 & PET-PMCP & $60.5 \pm 1.8$ & $17 \pm 1.6$ & 41.9 & 9.0 & 50.9 & 45 \\
\hline 3 & PET-PMP-dextrane & $55 \pm 2$ & $18 \pm 2.5$ & 38.9 & 15.5 & 54.4 & 27 \\
\hline 4 & PET-PMCPEG-dextrane & $50 \pm 2.6$ & $17 \pm 2.5$ & 38.3 & 18.6 & 57.9 & 38 \\
\hline 5 & PET + dextrane & $80 \pm 3$ & $25 \pm 1.5$ & 47.5 & 2.2 & 49.7 & - \\
\hline
\end{tabular}

Note: layers of PMP and PMCP were obtained on the surface of PET by spin coating applying the modifier from $5 \%$ solution. Heating time at $353 \mathrm{~K}$ in the dextrane solution was $120 \mathrm{~min}$.

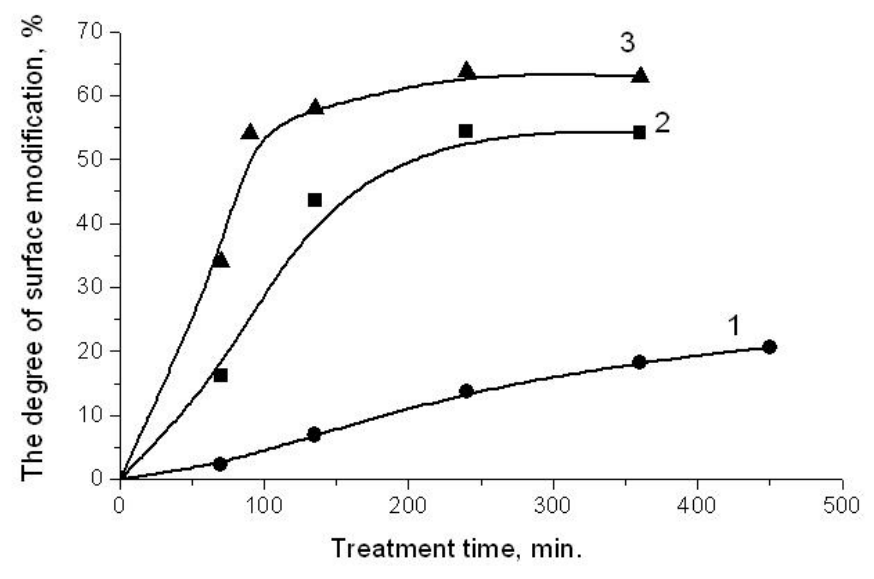

Fig. 3. Dependence of the modification degree of PET surface on the heating time: nanolayer of PMP on the surface at $343 \mathrm{~K}$ (curve 1); nanolayer of PMP on the surface at $353 \mathrm{~K}$ (curve 2); nanolayer of PMCP on the surface at $353 \mathrm{~K}$ (curve 3 )

The temperature of treatment is one of the main factors, which influences the regularities of formation of the attached oligoperoxide layer. Fig. 3 presents the curves of surface covering dependence on the time, obtained at $343 \mathrm{~K}$ and $353 \mathrm{~K}$ (curves 1 and 2). It is clearly seen that there are significant deviations in both speed and efficiency of surface modification at different temperatures. At $343 \mathrm{~K}$ efficiency of modification is 2.5 times lower than at $353 \mathrm{~K}$, besides, not more a $20 \%$ of the surface can be modified.

Certain distinctions between curves 2 and 3 (Fig. 3) (PMP and PMCP, respectively), are caused by the presence of chloroanhydride groups as well as more intensive decomposition of peroxy groups in oligoperoxide PMCP, therefore the modification process goes faster.

Formation of covalently attached layer of oligoperoxide on the surface of PET, with uniform distribution of peroxy groups of identical nature on the surface, allows to install additional dextrane modifying layers (dextrane with MM approx.3000). The modification of peroxidated surface with dextrane was controlled via changing the wetting angles of two liquids on both modified and original surfaces of PET. Table 2 shows the parameters of the free surface energy of modified surfaces as well as the modification degree.

Table 2 shows that after activation of PET surface by attaching of oligoperoxide, the possibility of dextrane macromolecules installing appears. It is obvious from the sufficient increasing of the hydrogen component of free surface energy. Simultaneously unmodified plates of PET 
do not change their surface characteristics after the same treatment in a dextrane solution.

\section{Conclusions}

The possibility of dextrane macromolecules grafting to the peroxidized surface of PET has been illustrated. The peroxidation of the surface has been proceeded by immobilization of peroxide oligomers and active oligoperoxides, which have functional chloroanhydride groups. The developed method allows to reach the degree of surface modification of more than $50 \%$. The dependence between the modification degree and modifier concentration in the initial solution, temperature and termination of treatment hasbeen investigated.

\section{Acknowledgments}

We appreciate a financial support of this work, which was provided by GFFI of Ukraine (Grant GP/F13/ 0010).

\section{References}

[1] Al-Malaika S. (Ed): Reactive modifiers for polymers. London 1997.

[2] Ando W.: Organic peroxides. Chichester 1992.

[3] Minko S., Luzinov I., Evchuk I., Voronov S.: Polymer, 1996, 37, 177.

[4] Bartlett P.: Peroxide reaction mechanisms. New York 1981.

[5] Nosova N.: PhD thesis, Lviv 2002.

[6] Stetsyshyn Ju.: PhD thesis, Lviv 2005.

[7] Samaryk V., Roiter Ju., Nosova N. et al.: Dopovidi Nats. Akad. Nauk Ukrainy, 2004, 4, 136.
[8] Dictionary of organic compounds. New York-LondonToronto 1982.

[9] Weissberger A., Proskauer E., Riddick J. and Toups E.: Organic solvents. New York 1955.

[10] Milas N. and Surgenor D.: J. Amer. Chem. Soc., 1946, 68, 205.

[11] Antonovski V.: Organicheskije perekisnyje initsiatory. Moscow 1972.

[12] Dickej F. et al.: J. Amer. Chem. Soc., 1979, 71, 1432.

[13] Houben W.: Methoden der Organishen Chemie. Stuttgart 1952.

[14] Jenkins D. and Hudson S.: Chem. Rew, 2001, 101, 3245.

[15] Gu Y.: Encyclopedia of surface and solloid science. New York 2002.

[16] Swain P. and Lipowsky R.: Langmuir, 1998, 14, 6772.

[17] Van Krevelen D.: Svojstva i himiceskoe stroenie polimerov. Moskva 1976.

[18] Nosova N., Roiter Yu., Samaryk V., et al.: Macromolecular Symposia, 2004, 210, 339.

\section{ОСНОВНІ ЗАКОНОМІРНОСТІ МОДИФІКАЦІЇ ПОВЕРХНІ ПОЛІЕТИЛЕНТЕРЕФТАЛАТУ ОЛІГОПЕРОКСИДАМИ}

\begin{abstract}
Анотація. Проведено модифікацію поверхні поліетилентерефталату новими олігопероксидними модифікаторами на основі тетрахлорангідриду піромелітової кислоти, ПЕГ-9 та трет-бутилпероксиметанолу. Розроблений метод дозволяє досягнути ступенів модифікації поверхні до 64 \%. Показана можливість прищеплення до пероксидованої поверхні макромолекул декстрану. Встановлено залежності між ступенем модифікації поверхні та кониентрацією модифікатора у розчині, температурою та часом прогрівання.
\end{abstract}

Ключові слова: активація, модифікація, полімерна поверхня, олігопероксиди, поліетилентерефталат. 